\title{
Intercultural competence in Higher Education: academics' perspectives
}

\begin{tabular}{|r|l|}
\hline Journal: & On The Horizon \\
\hline Manuscript ID & OTH-02-2018-0011.R1 \\
\hline Manuscript Type: & Research Paper \\
\hline Keywords: & intercultural competence, higher education, internationalization, academics \\
\hline \multicolumn{2}{|l}{} \\
\hline
\end{tabular}

\section{SCHOLARONE" \\ Manuscripts}

This is an Author Accepted Manuscript (post-print) of an article published as EarlyCite by Emerald Insight in On the Horizon on 10 July 2018, available at https://www.emeraldinsight.com/ doi/abs/10.1108/OTH-02-2018-0011

To cite this document:

Pinto, S. (2018). Intercultural competence in Higher Education: academics' perspectives. On The Horizon. (DOI:10.1108/OTH-02-2018-0011). 
Intercultural competence in Higher Education: academics' perspectives

\begin{abstract}
Purpose - The purpose of this study is to diagnose and understand Portuguese academics' perspectives on the components of Intercultural Competence and on the importance of its development by higher education students.

Design/methodology/approach - Academics' perspectives were identified during two discussion and reflection sessions included in the overall training program Intercultural Competence in Higher Education: building proposals with academics that took place at a Portuguese public university. Data was collected through audio recordings of the two sessions and observation notes, and was subject to content analysis drawing on Deardorff's Process Model of Intercultural Competence (2006).

Findings - Academics recognize the multidimensionality of intercultural competence, acknowledging it comprises attitudes (acceptance and respect; curiosity and openness), knowledge (others' cultural contexts; self-knowledge and cultural self-awareness) and skills (observation and listening) that altogether will lead to individuals' desired internal and external outcomes. The development of intercultural competence by higher education students, regarded in close relation to higher education internationalization, is considered crucial for changing prejudiced attitudes, preparing students to live in a global world, and empowering them professionally.

Originality/value - The study sheds light on an issue that has been insufficiently addressed by research: academics' perspectives on intercultural competence development, namely in the Portuguese higher education context.
\end{abstract}

Keywords intercultural competence; higher education; internationalization; academics

Paper Type Research Paper

\title{
Intercultural competence: a focus and outcome of higher education internationalization
}

One of the most pressing concerns currently faced by Higher Education Institutions (HEI) is the development of transversal skills by students, in addition to technical and scientific ones, to enhance their integration in national and international job markets, their mobility and their ability to live in a diverse world (Deardorff, 2015 Griffith et al., 2016; Stier, 2006). In this framework, and in the context of a current rise in nationalism, populism and isolationist tendencies, the development of Intercultural Competence (IC) in higher education assumes a crucial significance as shown by extensive research (Deardorff, 2004, 2006; Deardorff \& Jones, 2012; Dimitrov et al., 2014).

IC has been perceived as a higher education transversal learning outcome whose importance is twofold: the need to prepare graduates who are able to address global challenges, acting in an integrated world system, and to resolve intercultural conflicts (Council of Europe, 2008; Deardorff \& Arasaratnam-Smith, 2017); and the need for HEI internationalization which has increasingly become a key theme at global level (Deardorff \& Arasaratnam-Smith, 2017; de Wit et al., 2017; Egron-Polak \& Hudson, 2014). Within internationalization, IC acquires a relevant 
position as perceived in Knights' definition: "Internationalization at the national/sector/institutional level is defined as the process of integrating an international, intercultural or global dimension into the purpose, functions or delivery of post-secondary education" (2004, p. 11). This dimension is also present in the social/cultural rationale, which along with political, economic and academic rationales may drive $\mathrm{HEI}$ internationalization. According to Knight (2004), the social/cultural rationale is related to the importance given to knowledge of the Other, his/her language and culture, assuming that intercultural dialogue and peace are dependent on intercultural understanding and communication. In this sense, the development of graduates' IC is considered one of the strongest rationales for internationalizing higher education.

The concept of internationalization at home, which has been receiving more attention in the past fifteen years, also puts an emphasis on (home) students' IC: "Internationalisation at Home is the purposeful integration of international and intercultural dimensions into the formal and informal curriculum for all students within domestic learning environments" (Beelen \& Jones, 2015, p. 76). Likewise, internationalization of the curriculum, as defined by Leask (2015), underlines this intercultural dimension in $\mathrm{HEI}$ internationalization, and is defined as "...the incorporation of international, intercultural and/or global dimensions into the content of the curriculum, as well as the learning outcomes, assessment tasks, teaching methods and support services of a program of study" (p. 9), so as to develop students' international and intercultural perspectives as global citizens.

The way higher education internationalization has been related to the development of students' IC, assigns academics a central role, presenting them with the challenge of being drivers of intercultural education as "a pedagogy - aims, content, learning processes, teaching methods, syllabus and materials, and assessment - of which one purpose is to develop intercultural competence in learners of all ages in all types of education as a foundation for dialogue and living together" (Council of Europe, 2014, p. 27). Indeed, the success of this pedagogy is very dependent on academics that, regardless of their disciplinary areas, have a responsibility in the development of their students' IC.

In order for them to fulfill this responsibility, they need to:

- become aware of the importance of developing their students' IC (Ouellett, 2005);

- attain IC themselves (Cushner \& Mahon, 2009; Deardorff, 2009);

- be supported by their institutions in the construction of clear educational policies that meet the development of IC (Hiller, 2010);

- have opportunities to explore IC frameworks and ways in which they can be translated into intercultural learning outcomes within curricula (Gopal, 2011);

- have training within intercultural skills programs to develop their intercultural teaching competence and to help them model and guide students' IC development (Deardorff \& Jones, 2012; Dimitrov et al., 2014).

Some universities worldwide have been taking long-term holistic approaches to support staff and academics in achieving this transformation (see Leask, 2009, for the Australian context; Jones \& Killick, 2013, for the United Kingdom; Childress, 2010, for the United States of America; van Gaalen et al., 2014, for the Netherlands). Usually these approaches begin with an analysis of institutional policies and afterwards opportunities for sharing, joint learning and reflection are created.

Acknowledging the relevance of the approaches undertaken by these universities, it is important to pay a more initial attention to academics' perspectives on IC development. As highlighted by Paige and Goode (2009), literature on intercultural training overwhelmingly views intercultural competence from the perspective of the students, and there remains insufficient conceptualization of intercultural learning on the part of the teachers. In addition 
to this, a growing body of research literature shows that teachers beliefs' and perspectives directly affect their perceptions of both teaching and learning in the classroom, and therefore, affect their practices as highlighted by Borg: “...teachers are active, thinking decision-makers who make instructional choices by drawing on complex practically-oriented, personalized, and context-sensitive networks of knowledge, thoughts, and beliefs" (2003, p. 81). Hence, more studies focused on academics' perspectives concerning IC development are needed since these perspectives may influence practices and discourses. The aim of this study is, therefore, to shed light on this issue.

\section{The study: Portuguese academics' perspectives on intercultural competence \\ Discussion and Reflection Sessions: IC in Higher Education}

Between November 2016 and December 2016 a set of four two-hour sessions of discussion and reflection entitled Intercultural Competence in Higher Education: building proposals with academics took place at a Portuguese public university. These sessions, supported by the Rectory, were aimed at academics (an invitation was sent to all academics via the Rectorate and online registration was required) and were based on collaborative work that could boost the (re)construction of knowledge and practices regarding the development of students' IC. The following overall goals were pursued: to deepen knowledge on how to promote and assess IC development; to analyze existing practices of IC development in higher education; to collaboratively build strategies contributing to the development of higher education students' IC.

Each session also included specific objectives and involved diverse activities as summarily presented in Table 1:

Table 1. Session objectives and activities

Given the issues raised in the first section of this paper, and considering the identified research gap concerning academics' perspectives about IC, this paper will focus on data collected in the first two sessions. These allowed: i) diagnosing academics' perspectives concerning the components of IC; ii) understanding the importance given by academics to the development of IC by higher education students.

\section{Participants}

A total of 10 academics participated in the two sessions. These academics ( 7 female and 3 male, aged between 35 and 60 years old) conducted teaching and/or research activities in diverse disciplinary areas (Table 2):

Table 2. Participants' disciplinary areas

This diversity of disciplinary areas shows that, somehow, intercultural education is a concern shared by academics teaching "about the social world and/ or the world of the individual human being", but also by academics who "teach about the natural world" (Council of Europe, 2014, p. 33).

Apart from their teaching and research duties, some participants performed other roles in the institution: one was a Doctoral Program Director, one was a Master's degree vice-director, one 
was a Pro-Rector of the University. Furthermore, three participants were Post-Doctoral Research Fellows at the University. All signed informed consent forms prior to their participation in the study.

\section{Data collection and analysis}

Considering the research objectives, the following data sources were used: audio recordings of the two sessions and observation notes taken during the sessions. The session transcripts were analysed using the principles of content analysis (Bardin, 2001; Krippendorff, 2013).

Acknowledging that in the past fifteen years much scholarly effort has been invested in the definition of Intercultural Competence and that several models and frameworks have been designed according to disciplinary areas (Arasaratnam-Smith, 2017; Griffith et al., 2016), and considering that this study focuses on the higher education context, data will be analysed drawing on Deardorff's Process Model of Intercultural Competence (2006). This (grounded research-based) compositional model achieved consensus among twenty-three top experts on intercultural competence and was validated by higher education administrators. For these reasons, and because it focuses on identifying and assessing IC as a student outcome of HE internationalization, it has been widely influential in higher education.

Deardorff defines IC as "the ability to communicate effectively and appropriately in intercultural situations based on one's intercultural knowledge, skills and attitudes" (2004, p. 194). Attitudes are considered the fundamental starting point in developing IC, having an impact on all other aspects and comprise: respect (valuing other cultures, cultural diversity), openness (to intercultural learning and to people from other cultures, withholding judgment), curiosity and discovery (tolerating ambiguity and uncertainty). Knowledge and comprehension comprise cultural self-awareness, deep understanding and knowledge of culture (including contexts, role and impact of culture and others' world views), culture-specific information and sociolinguistic awareness. Skills of observation and interpretation, analysis, evaluation and relation are necessary to acquire knowledge but also to make meaning of that knowledge and then apply it in specific situations.

These three components lead to desired internal and external outcomes. Desired internal outcomes involve "an internal shift in frame of reference" (Deardorff, 2004, p.196), and comprise adaptability (to different communication styles and behaviors, adjustment to new cultural environments), flexibility (selecting and using appropriate communication styles and behaviors, cognitive flexibility); ethnorelative view and empathy. These outcomes, which occur within the individual as a result of the acquired attitudes, knowledge and skills, will lead to Desired external outcomes that can be described as "behaving and communicating appropriately and effectively in intercultural situations" (Deardorff, 2004, p.196).

This model, which perceives IC development as a lifelong process, reveals the developmental nature of IC that starts with appropriate individual attitudes, emphasizing a movement from the personal level to the interpersonal one.

\section{Results}


According to the outlined research objectives, results are presented and discussed according to two main themes: Academics' perspectives on the components of intercultural competence and Importance of developing higher education students' intercultural competence. Participants' names were changed to preserve anonymity and their statements are illustrated by quotations, translated into English, providing representative perspectives of the participants.

\section{Academics' perspectives on the components of intercultural competence}

Academics emphasize the complexity of IC, highlighting that it may undertake different "nuances" according to one individual's experiences and life stories: "It is a complex concept that can be and mean many things, depending on each person's life experiences and on the contexts people move in" (Andreia).

Recognizing the complexity inherent to the concept, they highlight that it is composed of different interrelated components - attitudes, knowledge and skills - that altogether will ideally lead to change in individual's internal frames of empathy and adaptability, as well as to effective and appropriate communication in intercultural situations. Although emphasis is highly placed on attitudes and knowledge, academics also recognize the importance of skills, underlining that, for instance, "Knowing foreign languages and knowing different cultures does not mean that you have intercultural competence. Having intercultural competence is much more than that... it is being, knowing and acting" (Francisco).

Attitudes are considered the foundation of IC because they are "The basis for someone to behave interculturally because they have an impact on the other features of intercultural competence" (Jacinta). Attitudes towards otherness are the most valued by academics and are related to the relationship that individuals establish with others. In this sense, academics highlight the fundamental need to accept and respect people from different cultural backgrounds: "If we are not able to respect people from different parts of the world and their viewpoints, we will not be able to communicate with them" (João). They also underline the importance of curiosity towards others and openness, emphasizing that "Having an open mind is crucial for individuals to engage in intercultural dialogue" (Marta). Hence the notion of 'otherness', which is at the core of IC, is strongly stressed by academics.

Concerning Knowledge, our data shows that academics put emphasis on the need to "Know different realities and contexts" (Andreia) and "Know the history, customs, perspectives and ways of being and living of the Other" (Gabriela). Hence, knowing others' cultural contexts and worldviews, which includes knowing historical, political and social contexts and goes beyond conventional surface-level knowledge of foods, customs and festivities, is highly valued. This type of knowledge is considered essential in the sense that it can avoid misunderstandings in intercultural interactions: "If we do not know other people's customs and the realities they live in, we risk making mistakes and misinterpretations" (Francisco). Academics also highlight the need for self-knowledge and cultural self-awareness that may help individuals better understand others: "It is important to know ourselves, to understand our own ways of doing things and how we react to situations... It is important to question our principles and our knowledge ... only then will we be able to understand others" (Jacinta).

Regarding Skills, the least mentioned component, academics emphasise the importance of observation and listening: "It is important to see, to really see the Other and listen to him/her so that we can know more about him/her" (Marta). This shows that they believe that observing and listening, which are part of critical thinking skills, are important to acquire knowledge to be mobilized in intercultural situations.

Concerning Desired internal outcomes, academics believe the above attitudes, knowledge and skills are crucial for individuals to be able to show empathy towards the Other and to adapt to 
different cultural environments: "Having intercultural competence means that you are sensitive to 'difference', that you know other realities and that you are able to interpret those realities; only when you do that, will you be able to adjust yourself to the Other, not imposing our own perspectives and being able to put yourself in others' shoes" (Gabriela). Moreover, academics believe that the combination of attitudes, knowledge, skills and desired internal outcomes is demonstrated through the visible behavior and communication of the individual (Desired external outcomes): "When we interact with foreign students in our classes, it is important to make use of the intercultural attitudes, knowledge and skills necessary to communicate with them" (Jorge).

This analysis shows that academics perceive IC as being multidimensional, and articulating different dimensions that are intimately interdependent within a holistic approach, therefore, meeting what is underlined by Deardorff $(2004,2006,2015)$. Within these dimensions, they identify foundational attitudes to further develop the knowledge and skills needed for intercultural competence. Moreover, academics stress that the development of IC is an ongoing process and that "Students do not develop it just because they study abroad or because they engage in intercultural encounters sometimes" (Gabriela).

\section{Importance of developing higher education students' intercultural competence}

All academics consider that developing higher education students' IC is increasingly important, underlining reasons that can be grouped in three interrelated categories: changing prejudiced attitudes, preparing students to live in a global world and empowering them professionally.

Academics believe that higher education students must develop IC so as to change prejudiced attitudes into attitudes of respect, openness, curiosity and discovery. This attitude change becomes more important because, as academics underline, interaction between people from diverse backgrounds and cultural contexts is greater than ever due to technological advances that increase physical and virtual mobility. Hence, they emphasize that enhancing students' IC will "Contribute to an openness of mind towards the world and knowledge which is crucial to make societies work" (Beatriz), enabling them to "Better deal with constraints and cultural differences and to interact with different people in diverse cultural contexts" (Andreia).

Changing prejudiced attitudes is intimately related to the need for students to be prepared to live in a global world that is characterized by linguistic and cultural diversity. This preparation includes acquiring "Knowledge and understanding of different cultures and social contexts" (Maria) that will contribute to make students more "Sensitive to difference, to other ways of thinking and acting allowing them to reflect not only about others but also about themselves" (Jacinta). Thus, academics underline the need for students to develop an ability to see things from others' perspectives so that they can act in a global world. This will, in turn, help them learn and reflect critically about their own cultural positioning, beliefs, discourses and values. So, academics believe that IC not only enhances students' knowledge and understanding of other people, but it also promotes self-knowledge and self-understanding.

Moreover, it is worth noting that academics place an emphasis on the importance of developing IC by home students who do not participate in study abroad programs: "It is important that students who never engage in mobility have the chance to develop their intercultural competence 'at home' because they will also have to act both locally and globally" (Gabriela). In this line of thought, academics emphasize the need to teach their students to understand the interdependencies between local and global contexts, so as to become citizens "able to address global challenges and live in an interconnected society" (Deardorff \& Jones, 2009, p. 283). These perspectives show that academics believe that IC "enables people to interact and cooperate effectively and appropriately in situations where 
cultural 'otherness' and 'difference' are salient" (Council of Europe, 2014, p. 23), relating it to concepts such as social cohesion and civic engagement.

Being able to work effectively across cultures as a way of achieving professional empowerment was also identified as an important reason for higher education students to develop IC: "It is important to prepare our students to be able to work in the global market, to be competitive professionally" (Sandra); "They must understand that without this kind of competences they will not have the tools to work neither in Portugal nor abroad" (Andreia). Again, academics focus on students who do not participate in study abroad programs underlining that "Those students will also need to be interculturally competent to be successful in their professional future... internationalization is not only aimed at those who study abroad" (Sandra).

These perspectives are in accordance with the results of several reports focusing on required professional skills by employers, which have identified IC as a crucial competence in today's intercultural workplace (Association of American Colleges and Universities, 2015; British Council, 2013). Indeed, academics are aware that "Many jobs today, regardless of location, require working with other people who are quite different from each other. While technical knowledge and subject knowledge are certainly important for success, they are not enough" (Deardorff, 2015, p.137).

Considering the importance attached to the development of students' IC, academics underline that they should be given diversified opportunities to develop this competence overtime: study abroad, on-campus interaction with foreign students, course work (which implies that teachers are able to introduce the development of IC in their course units), as well as initiatives taken by the university that foster relationships between Portuguese and foreign students. Thus, academics point out two main strategies to develop students' intercultural competence: through the curriculum and through co-curricular activities (organized by the university), which combined may bring an intercultural dimension to students' educational experiences. When talking about the curriculum, academics admit that it is hard for them to integrate the development of IC in their course units because they believe they do not know the concept well enough "Being hard to translate attitudes, skills and knowledge into clear and assessable learning outcomes" (Andreia).

\section{Discussion and concluding remarks}

This study allowed diagnosing Portuguese academics' perspectives concerning the components of IC, and understanding the importance they attach to the development of IC by higher education students. Regarding the first aspect, results suggest that academics acknowledge the complexity of IC, referring to it as multidimensional and considering its development an ongoing process. They recognize that it is composed of attitudes (acceptance and respect; curiosity and openness), knowledge (others' cultural contexts; self-knowledge and cultural selfawareness) and skills (observation and listening), which altogether will lead to individuals' desired internal and external outcomes.

As what concerns the importance they attach to the development of IC by higher education students, results show that all academics believe this is crucial for two main rationales: a more "humanistic" one related with the need to change prejudiced attitudes and prepare students to live in a diverse world; and a more "economic" one related with the need to empower students professionally. They believe IC can be taught and students should be given diversified opportunities to develop it within curricular and co-curricular activities. Nevertheless, they do not feel prepared to integrate this dimension in their teaching practices, namely in their course units. 
Acknowledging the role of $\mathrm{HEI}$ as agents of intercultural understanding and the need to embed an international and intercultural perspective in their overall activities (Egron-Polak \& Hudson, 2014), results highlight a crucial issue concerning policy and practice in Portuguese universities: the need to recognize academics' central role in intercultural education and, consequently, in institutions' internationalization. Recognizing this role implies that universities take on the responsibility of contributing to the development of academics' intercultural teaching competence (Deardorff, 2009; Dimitrov et al., 2014).

If academic staff plays a key role in developing students' IC, it is fundamental that institutions "Implement intercultural skills training programs to help prepare staff to model and guide students' intercultural competence development" (Deardorff \& Jones, 2012, p. 280). Moreover, as highlighted by Murray (2016) "It is incumbent upon institutions to ensure that their teacher-training and professional development programs foster the intercultural competence of teachers" (p. 168).

Indeed, in a context where most academics have no formal teacher training (Borralho, Fialho, \& Cid, 2012), providing them with possibilities of developing their own IC and learning how to embed it in curricula is imperative. Hence, it is important that Portuguese universities create spaces of reflection and collaboration (Marcelo García, 2009), integrating academics from different disciplinary areas, which potentiate experience-sharing and the reconstruction of knowledge and practices concerning the development of IC by higher education students.

This was the main goal of the program Intercultural Competence in Higher Education: building proposals with academics, which allowed academics to jointly discuss and reflect on some central questions. Therefore, following Deardorff's recommendations $(2011,2015)$, this space was an initial trigger for reflection on some crucial questions such as: what is IC and why is it important? What intercultural skills and knowledge should our students have in the present globalized world? What role can academics and institutions play in mentoring students in IC development? This joint reflection, highly valued by the academics who participated in the program, can function as a prior stage to support them and $\mathrm{HEI}$ in embedding IC development not only into the core of the curriculum but also into their overall activities, within a comprehensive approach to internationalization.

\section{References}

Association of American Colleges and Universities (2015). Falling short? College learning and career success. Retrieved from https://www.aacu.org/leap/public-opinion-research/2015survey-results

Arasaratnam-Smith, L. (2017). Intercultural competence: An overview. In D. Deardorff \& L. Arasaratnam-Smith (Eds.), Intercultural competence in higher education. International approaches, assessment and application (pp.7-19). New York: Routledge.

Bardin, L. (2001). L'analyse de contenu [Content analysis]. Paris: Presses Universitaires de France.

Beelen, J., \& Jones, E. (2015). Redefining internationalization at home. In A. Curai, L. Matei, R. Pricopie, J. Salmi \& P. Scott (Eds.), The European Higher Education Area: Between critical reflections and future policies (pp. 67-80). Dordrecht: Springer.

Borg, S. (2003). Teacher cognition in language teaching: A review of research on what language teachers think, know, believe, and do. Language Teaching, 36, 81-109.

Borralho, A., Fialho, I., \& Cid, M. (2012). Aprendizagem no ensino superior: relações com a prática docente [Learning in higher education: relationships with teaching practice]. In C. Leite 
\& M. Zabalza (Eds.), VII Congresso IberoAmericano de Docência Universitária - Ensino Superior: Inovação e qualidade na docência (pp. 984-996). Porto: CIIE - Centro de Investigação e Intervenção Educativas.

British Council (2013). Culture at work. Retrieved from https://www.britishcouncil.org/sites/default/files/culture-at-work-report-v2.pdf

Childress, L. (2010). The twenty-first century university: Developing faculty engagement in internationalisation. New York: Peter Lang.

Council of Europe (2014). Developing intercultural competence through education. Pestallozzi Series no. 3. Strasbourg: Council of Europe Publishing.

Council of Europe (2008). White paper on intercultural dialogue. Retrieved from https://www.coe.int/t/dg4/intercultural/source/white\%20paper final revised en.pdf

Cushner, K., \& Mahon, J. (2009). Intercultural competence in teacher education. Developing the intercultural competence of educators and their students. In. D. Deardorff (Ed.), The Sage handbook for intercultural competence (pp. 304-320). Thousand Oaks, CA: Sage Publications.

De Wit, H., Gacel-Ávila, J., Jones, E., \& Jooste, N. (2017). The globalization of internationalization: Emerging voices and perspectives. Abingdon: Routledge.

Deardorff, D. (2015). A 21st century imperative: Integrating intercultural competence in Tuning. Tuning Journal for Higher Education, 3(1), 137-147.

Deardorff, D. (2011). Assessing intercultural competence. New Directions for Institutional Research, 149, 65-79.

Deardorff, D. (2009). Exploring interculturally competent teaching in social sciences classrooms. EliSS, 2(1), 1-18.

Deardorff, D. (2006). Identification and assessment of intercultural competence as a student outcome of internationalization. Journal of Studies in International Education, 10, 241-266.

Deardorff, D. (2004). The identification and assessment of intercultural competence as a student outcome of internationalisation at institutions of higher education in the United States. Unpublished PhD thesis. http://repository.lib.ncsu.edu/ir/bitstream/1840.16/5733/1/etd.pdf

Deardorff, D., \& Arasaratnam-Smith, L. (2017). Introduction. In D. Deardorff \& L. ArasaratnamSmith (Eds.), Intercultural competence in higher education. International approaches, assessment and application (pp. 1-4). New York: Routledge.

Deardorff, D., \& Jones, E. (2012). Intercultural competence: An emerging focus in postsecondary education. In D. Deardorff, H. de Wit, J. Heyl \& T. Adams (Ed.), The Sage handbook of international higher education (pp. 283-302). Thousand Oaks, CA: Sage.

Dimitrov, N., Dawson, D., Olsen, K., \& Meadows, K. (2014). Developing the intercultural competence of graduate students. Canadian Journal of Higher Education, 44(3), 86-103.

Egron-Polak, E., \& Hudson, R. (2014). Internationalization of higher education: Growing expectations, fundamental values. IAU 4th Global Survey. Paris: International Association of Universities.

Gaalen, A. van, Hobbes, H.J., Roodenburg, S., \& Gielesen R. (2014). Internationalising students in the home country - Part I. The Hague: Nuffic, Global Dialogue Declaration on the Future of Internationalisation of Higher Education, EAIE. Retrieved from https://www.nuffic.nl/en/publications/find-a-publication/management-summaryinternationalising-students-in-the-home-country.pdf

Griffith, R., Wolfeld, L., Armon, B., Rios, J., \& Liu, O. (2016). Assessing intercultural competence in higher education: Existing research and future directions. Retrieved from http://onlinelibrary.wiley.com/doi/10.1002/ets2.12112/full 
Gopal, A. (2011). Internationalization of higher education: Preparing faculty to teach crossculturally. International Journal of Teaching and Learning in Higher Education, 23(3), 373-381.

Hiller, G. (2010). Innovative methods for promoting and assessing intercultural competence in higher education. Proceedings of Intercultural Competence Conference, 1, 144-168.

Jones, E., \& Killick, D. (2013). Graduate attributes and the internationalised curriculum: Embedding a global outlook in disciplinary learning outcomes. Journal of Studies in International Education, 17(2), 165-182.

Knight, J. (2004). Internationalization remodeled: Definition, approaches, and rationales. Journal of Studies in International Education, 8, 5-31.

Krippendorff, K. (2013). Content analysis. An introduction to its methodology. Los Angeles: Sage.

Leask, B. (2015). Internationalizing the curriculum. London: Routledge.

Leask, B. (2009). Using formal and informal curricula to improve interactions between home and international students. Journal of Studies in International Education, 13(2), 2015-221.

Marcelo García, C. (2009). Desenvolvimento profissional docente: passado e futuro [Teachers' professional development: past and future]. Sísifo. Revista de Ciências da Educação, 8, 7-22.

Murray, N. (2016). Dealing with diversity in higher education: awareness raising and a linguistic perspective on teachers' intercultural competence. International Journal for Academic Development, 21(3), 166-177.

Ouellett, M. L. (2005). Teaching inclusively. Stillwater, OK: New Forums Press.

Paige, R., \& Goode, M. (2009). Cultural mentoring: International education professionals and the development of intercultural competence. In D. Deardorff (Ed.), The SAGE handbook of intercultural competence (pp. 333-349). Thousand Oaks, CA: Sage.

Stier, J. (2006). Internationalisation, intercultural communication and intercultural competence. Journal of Intercultural Communication, 11, 2-12. 
Table 1. Session objectives and activities

\begin{abstract}
Session 1. Intercultural competence in higher education: what and why?
Objectives: Stimulate reflection and share perspectives on the concept of IC; deepen knowledge about IC and its components.

Activities: i) Brainstorming on the concept of IC; ii) Analysis and discussion of Deardorff's Process Model of Intercultural Competence (2006)
\end{abstract}

\title{
Session 2. Curricula and the development of intercultural competence
}

Objectives: Stimulate reflection on the importance of developing higher education students' IC and on the intercultural attitudes, knowledge and skills they need to develop; analyze and reflect on intercultural learning outcomes.

Activities: i) Brainstorming on the importance of IC development by students; ii) Analysis of intercultural learning outcomes from different courses/universities.

\section{Session 3. Development of intercultural competence: proposals for curriculum design}

Objectives: Design intercultural learning outcomes for their own course units; reflect on the need to align intercultural learning outcomes with course contents, pedagogical strategies, activities, resources and assessment.

Activities: i) Analysis and reformulation of courses learning outcomes; ii) Redesigning courses syllabus (alignment of learning outcomes, contents, strategies, activities, resources and assessment).

\section{Session 4. Sharing proposals of curriculum (re)design}

Objectives: Discuss and reflect on the potentialities and difficulties of integrating IC in courses syllabus.

Activities: Presentation and discussion of the proposals for curriculum (re)design. 
Table 2. Participants' disciplinary areas

\begin{tabular}{l|l}
\hline Fictional names & Disciplinary area \\
\hline Andreia & Accountancy and Administration \\
\hline Beatriz & Educational Sciences \\
\hline Francisco & Accountancy and Administration \\
\hline Gabriela & Language and Cultural Studies \\
\hline Jacinta & Language and Cultural Studies \\
\hline João & Civil Engineering \\
\hline Jorge & Mechanical Engineering \\
\hline Maria & Educational Sciences \\
\hline Marta & Educational Sciences \\
\hline Sandra & Health Sciences \\
\hline
\end{tabular}

